\title{
Study on the Regional Differences of Construction Land Efficiency in Sichuan Province
}

\author{
Wei He, Jiao Liu \\ School of Geographic and Resources Science, Sichuan Normal University, Chengdu, China \\ Email: cdwhe@163.com
}

Received 22 October 2015; accepted 6 December 2015; published 10 December 2015

Copyright (C) 2015 by authors and OALib.

This work is licensed under the Creative Commons Attribution International License (CC BY). http://creativecommons.org/licenses/by/4.0/

(c) (i) Open Access

\begin{abstract}
Using data derived from Sichuan Statistical Yearbooks and investigations of land-use change, the present research does a DEA-model study of regional differences in overall input-output efficiencies of construction land in the economic development of Sichuan province between 1999 and 2012. It finds that though in all land-use regions of the province the overall input-output efficiencies of construction land maintain a comparatively high standard, in some regions they are not in complete accordance with local economic development level. In addition, there are obvious disparities in the change patterns of the overall input-output efficiencies in different land-use regions. This paper then suggests that the function of adjustment, which the optimal allocation of construction land can play, should be brought into full effect to enhance regional socio-economic development, and that the allocation of construction land should be based on a comprehensive analysis of overall efficiency.
\end{abstract}

\section{Keywords}

Sichuan Province, Construction Land, Land-Use Regions, DEA Method, Overall Efficiency

Subject Areas: Development Economics

\section{Introduction}

Regional economic development is the combined result of essential factors of production, namely capital, labor, land and technology. Since the total amount of these four inputs, their quality, as well as their productivity, are crucial to economic development, it is understandable that the rapid development of economy will place growing demands on land resources [1].

As an economic power in Western China, Sichuan province displays noticeable regional varieties regarding 
land conditions and economic growth in different areas of the province. The Overall Plan of Sichuan Province for Land Use (2006-2020) divides the whole province into five land use regions. How efficiently construction land has been utilized in these five regions has decided the remarkably different ways in which it has functioned in their respective economic development. A comparative study of the contribution rates of construction land to economic growth in these regions will indicate its different functions as well as its varying utilization rates in these regions. In this way, this paper may provide necessary information as well as evidence concerning land use in Sichuan province, and the allocation optimization of construction land in particular.

Domestic researchers have done many studies on the contribution rates of land to economic growth. These studies, which are commonly based on panel data and modeled on production function [2], are usually empirical researches of China's economy or those of a representative region [3] [4]. Comprehensive as they are, these studies mainly analyze how the contribution rates of land in various cities or regions differ from each other. Without evaluating how in these cities or regions the contribution rates of land may tend to change, these studies fail to provide guidance on how to use land or how to plan land use in the future.

The present paper studies land use in Sichuan province. It uses data derived from Sichuan Statistical Yearbooks of 1999 through 2013 and investigations of land-use change to do a DEA-model study of five land use regions in the province. It contrasts and compares the varying contribution rates of construction land to economic development in these regions to examine their differences and to study how they may tend to change. In addition to this, it also offers decision-making advice regarding the allocation of construction land in these regions in the future.

\section{A General Survey of the Target Region}

\subsection{Land-Use Situation in Sichuan}

According to the Second National Land Survey, the total land area of the province is 48,611,636.85 acres. There are $6,719,964.21$ acres of cultivated land, accounting for $13.82 \%$ of the provincial total. Gardens cover $1.58 \%$ of the provincial total, i.e., 766,372.2 acres, whereas forest land accounts for 22,201,668.4 acres, covering 45.67\% of the total land area of the province. There are also12,231,906.99 acres of pastoral land, $25.16 \%$ of the provincial total, while land for residential and industrial facilities, land for transportation facilities, and land for water control facilities as well as water surface, cover 1,423,560.31 acres, 312,863.04 acres, and 1,030,912.6 acres respectively, accounting accordingly for $2.93 \%, 0.64 \%$, and $2.12 \%$ of the total provincial land area. The land that is left for future use amounts to $3,924,388.99$ acres, occupying $8.07 \%$ of the total land area of the province.

\subsection{Land-Use Regions in Sichuan}

Following the method for land use classification adopted by compliers of The Overall Plan of Sichuan Province for Land Use, 2006-2020, the present research also divides the whole province into five land use regions, namely the Chengdu Plain, Chuan'nan Region, Panxi Region, Chuandongbei Region, and Chuanxibei Region (Table 1). Based on the actual state of economic development in Sichuan province, this classification method takes into

Table 1. Land-use regions in Sichuan.

\begin{tabular}{cccc}
\hline Name & Sub-Regions & $\begin{array}{c}\text { Regional Land Area } \\
\left(10,000 \mathrm{~km}^{2}\right)\end{array}$ & $\begin{array}{c}\text { Percentage of the Total } \\
\text { Provincial Land Area }\end{array}$ \\
\hline $\begin{array}{c}\text { Chengdu Plain } \\
\text { Chuan'nan } \\
\text { Region } \\
\begin{array}{c}\text { Chuandongbei } \\
\text { Region }\end{array}\end{array}$ & $\begin{array}{c}\text { Five Prefecture-Level Cities, Namely Chengdu, } \\
\text { Deyang, Mianyang, Ziyang, and Meishan } \\
\text { Five Prefecture-Level Cities, Namely Zigong, Yibin, } \\
\text { Luzhou, Neijiang, and Leshan }\end{array}$ & 5.35 & $11.05 \%$ \\
Panxi Region & $\begin{array}{c}\text { Six Prefecture-Level Cities, Namely Guangyuan, } \\
\text { Suining, Nanchong, Guang'an, Dazhou, and Bazhong } \\
\text { Two Prefecture-Level Cities of Panzhihua and Ya'an, } \\
\text { and Liangshan Yi Autonomous Prefecture } \\
\text { Aba Tibetan and Qiang Autonomous Prefecture } \\
\text { and Ganzi Tibetan Autonomous Prefecture }\end{array}$ & 4.81 & $9.94 \%$ \\
Chuanxibei Region & - & 23.00 & $14.32 \%$ \\
Total & $\quad 48.61$ & $47.52 \%$ \\
\hline
\end{tabular}


consideration the characteristics of the land-use structure as well as the trends in land use in the province. It also reflects the functions designed for major functional zones in the province as stated in The Main Functional Zone Planning for Sichuan Province.

\section{Methodology and Sources of Data}

\subsection{Methodology}

Though economic development is a complex multi-input multi-output system, the DEA methodology has been widely employed to calculate the efficiency of factors of production to present a comparatively accurate picture of how their efficiency varies. It is for this reason that in the present research the C2R model of the DEA method will be employed.

This paper analyzes differences in the efficiency of construction land in economic development between 1999 and 2012 in the whole Sichuan province as well as that in the province's five land-use regions. Based on the comparability and accessibility of data as well as their relativity as an indication of the efficiency of construction land in economic development, the following input and output indexes are selected [5].

\subsubsection{Land Input}

In regional economic development, construction land, which is the most important part of land input, is basic to secondary and tertiary industries [6]. For this reason, this paper uses as indicators of land input the total area of construction land in the whole province as well as individual areas in the five land-use regions.

\subsubsection{Capital Input}

Capital input can either be identified as current year's capital stock or total investment in fixed assets. Since the present study employs the input-oriented C2R model to carry out its analysis, it selects as the indexes of capital input the total social investment in fixed assets in the whole province as well as that in the five land-use regions.

\subsubsection{Labour Input}

As construction land is basic to secondary and tertiary industries, the number of employees at year-end in these two categories of industries is cited to indicate the actual labour input. The present paper chooses this number as the index of labour input.

\subsubsection{Output}

As for output data, the present study, which calculates the efficiencies of construction land along with other factors, uses the gross output value of secondary and tertiary industries in the current year. This is because the output of construction land is mainly embodied in the gross output value of these two categories of industries.

\subsection{Sources of Data}

The data of the construction land studied are derived from investigation reports on land-use change in Sichuan province over the years. Other input-output data are derived Sichuan Statistical Yearbooks between the year 2000 and the year 2013.

\section{Results Analysis}

Basing on the input-oriented C2R model, the present research processes the index data mentioned above by using the DEAP software to calculate the efficiencies of capital, construction land, and labour in the economic development of the whole province as well as the five land-use regions between 1999 and 2012. See Table 2 for the results.

\subsection{On the Whole, the Overall Input-Output Efficiencies of Factors Maintain a Comparatively High Standard}

As is indicated in Table 2, between 1999 and 2012, the factors of construction land, investment in fixed assets, and labour achieved comparatively high input-output efficiencies in the economic development of Sichuan 
Table 2. Overall input-output efficiencies of factors in economic development of Sichuan province and land-use regions.

\begin{tabular}{ccccccccccccccccc}
\hline Region & 1999 & 2000 & 2001 & 2002 & 2003 & 2004 & 2005 & 2006 & 2007 & 2008 & 2009 & 2010 & 2011 & 2012 & Average \\
\hline $\begin{array}{c}\text { Sichuan } \\
\text { Province }\end{array}$ & 0.884 & 1 & 0.936 & 0.936 & 0.961 & 1 & 1 & 1 & 1 & 1 & 0.804 & 0.893 & 1 & 1 & 0.958 \\
$\begin{array}{c}\text { Chengdu } \\
\text { Plain }\end{array}$ & 1 & 1 & 0.979 & 0.979 & 1 & 1 & 0.919 & 0.915 & 0.93 & 0.903 & 0.733 & 0.869 & 0.974 & 1 & 0.943 \\
$\begin{array}{c}\text { Chuan'nan } \\
\text { Region }\end{array}$ & 0.868 & 1 & 0.935 & 0.951 & 0.932 & 0.996 & 1 & 0.997 & 1 & 0.998 & 0.825 & 0.868 & 1 & 1 & 0.955 \\
$\begin{array}{c}\text { Chuandongbei } \\
\text { Region }\end{array}$ & 0.937 & 1 & 0.944 & 0.948 & 0.931 & 1 & 0.972 & 0.976 & 1 & 1 & 0.863 & 0.871 & 1 & 1 & 0.960 \\
$\quad \begin{array}{c}\text { Panxi } \\
\text { Region }\end{array}$ & 1 & 1 & 0.972 & 0.966 & 0.922 & 0.925 & 0.985 & 0.963 & 1 & 0.873 & 0.715 & 0.822 & 0.895 & 1 & 0.931 \\
$\begin{array}{c}\text { Chuanxibei } \\
\text { Region }\end{array}$ & 1 & 0.997 & 1 & 0.963 & 0.928 & 0.967 & 0.988 & 0.966 & 1 & 1 & 0.781 & 0.828 & 0.979 & 1 & 0.957 \\
\hline
\end{tabular}

province, with an average ratio of 0.958. During this period of time, in the years of 2000, 2004-2008, 2011, and 2012, the overall efficiency ratio reached 1 , which indicates that there is DEA effectiveness in these eight years. In contrast, the overall efficiency ratio fell to the lowest of 0.804 in 2009, which was due to the effects of the 2008 Wenchuan Earthquake. In the aftermath of the earthquake, the central government made great efforts to support the reconstruction of disaster areas, approving favourable policies regarding construction land quota assignment as well as investment in fixed assets to ensure inputs, whereas this was not immediately revealed in the gross output value of secondary and tertiary industries in the current year.

\subsection{In Different Land-Use Regions, the Overall Input-Output Efficiencies of Factors Are Not in Complete Accordance with Local Economic Development Level}

As is also displayed in Table 2, of all the land-use regions in Sichuan province, between 1999 and 2012, it was in Chuan'nan Region that the factors achieved the highest input-output efficiency in local economic development, with an average ratio of 0.96. In terms of the average input-output efficiency ratio, Chuan'nan Region was followed consecutively by Panxi Region, Chuandongbei Region, and Chengdu Plain, while the lowest of 0.931 was found in Chuanxibei. This was not consistent with the corresponding economic development levels of these regions. In Table 3, the economic development levels of these regions, which are represented by the corresponding gross output value of secondary and tertiary industries in these regions in 2012, are compared with the input-output efficiency ratios of factors in these land-use regions.

As is made explicit in Table 3, in 2012 it was the land-use region of Chengdu Plain that achieved the largest regional gross output value of secondary and tertiary industries. However, the same land-use region witnessed an average overall input-output efficiency ratio of factors lower than that of either Chuan'nan Region, or Panxi Region, or Chuangdongbei Region. Chuan'nan region, the land-use region with the highest average overall input-output efficiency ratio, saw a much smaller regional gross output value of secondary and tertiary industries than that of Chengdu Plain. That is, the regional gross output value of secondary and tertiary industries of Chuan'nan regions was only 39\% of that of Chengdu Plain. The same disparity can also be noticed in the cases of Chuandongbei Region and Panxi Region. It was in the case of Chuanxibei Region that both the average overall input-output efficiency ratio and regional gross output value of secondary and tertiary industries were either the lowest or the smallest.

The main reason why the average overall input-output efficiency ratio in Chengdu Plain is not in complete accordance with local economic development level is that this land-use region plays an important role in the economic development of Sichuan province and even that of West China. The region is thus an economic hotspot. Its high economic development level attracts large amount of factors of production like capital and labour, while construction land quota assignment also favours this region. However, the accumulation of large quantities of factors of production can also lead to inequality among these factors, which will subsequently affect overall input-output efficiency. Eventually, the overall input-output efficiency ratio in Chengdu Plain fails to be compatible with its regional economic development level. 
Table 3. A comparison table of regional gross output value of secondary and tertiary industries and the average overall input-output efficiency ratio of factors in each land-use region in 2012.

\begin{tabular}{|c|c|c|c|c|c|}
\hline Land-Use Region & Chengdu Plain & Chuandongbei Region & Chuan'nan Region & Chuanxibei Region & Panxi Region \\
\hline $\begin{array}{l}\text { Regional Gross Output } \\
\text { Value of Secondary and } \\
\text { Tertiary Industries } \\
\text { (RMB Billion) }\end{array}$ & 1141.214 & 361.49 & 445.198 & 30.41 & 195.579 \\
\hline $\begin{array}{l}\text { Average Overall Input-Output } \\
\text { Efficiency Ratio of } \\
\text { Factors, 1999-2012 }\end{array}$ & 0.943 & 0.955 & 0.96 & 0.931 & 0.957 \\
\hline
\end{tabular}

\subsection{The Change Patterns of the Overall Input-Output Efficiency Ratios in Different Land-Use Regions Indicate Obvious Disparity}

A comparison of the change patterns of the overall input-output efficiency ratios in different land-use regions (Figure 1) shows that there are also obvious disparities between these change patterns. In the case of the landuse region of Chengdu Plain, its overall input-output efficiency ratio apparently tended to fall between 2005 and 2009, but rose again between 2010 and 2012. The overall input-output efficiency ratio of Panxi Region started to drop in 2008 until it reached its lowest in 2009, but also rose again between 2010 and 2012. Generally speaking, in the land-use regions of Chuandongbei, Chuan'nan and Chuanxibei, their overall input-output efficiency ratios did not vary greatly. However, there was still a marked drop in 2009 in these three regions which resulted in comparatively low efficiency ratios in 2010.

There are several reasons behind the obvious differences between these varying change patterns. As has been discussed in the previous part, the large quantities of factors invested in 2009 in the aftermath of Wenchuan Earthquake for the reconstruction of disaster areas resulted in low overall input-output efficiency ratios in the five land-use regions. Apart from this, the fact that the efficiency ratio already tended to dwindle between 2005 and 2008 in Chengdu Plain also makes clear that there was already inequality among factors of production in this land-use region prior to 2009. This is directly related to the excessive favour given to this land-use region regarding the allocation of resources and above all the assignment of construction land quota.

\section{Conclusions and Policy Advice}

\subsection{Conclusions}

Between 1999 and 2012, construction land achieved comparatively high overall input-output efficiency in the economic development of Sichuan province. The average efficiency ratio reached 0.958, and in the years of 2000, 2004-2008, 2011, and 2012, the overall efficiency ratio reached 1, which indicated that there was DEA effectiveness in these eight years.

During the 14 years covered in the present research, the highest efficiency ratio of factors was to be found in Chuan'nan land use region, with an average of 0.96. Chuan'nan Region was followed consecutively by Panxi land use region, Chuandongbei land use region, and Chengdu Plain land use region, while the lowest of 0.931 was found in Chuanxibei land use region. This was not in complete accordance with local economic development level.

There are obvious disparities in the change patterns of the overall input-output efficiency ratios in different land-use regions. The overall input-output efficiency ratio in Chengdu Plain apparently fell between 2005 and 2009, but rose again between 2010 and 2012. The overall input-output efficiency ratio of Panxi Region started to drop in 2008 but also rose again between 2010 and 2012. In the land-use regions of Chuandongbei, Chuan'nan and Chuanxibei, their overall input-output efficiency ratios did not vary greatly except for a marked drop in 2009 so that they were maintained at a comparatively high level.

\subsection{Policy Advice}

This paper suggests that the provincial government bring into full effect the function of adjustment which the optimal allocation of construction land can play to enhance regional socio-economic development. At present, construction land has become an important factor of production in regional economic growth and is now playing 


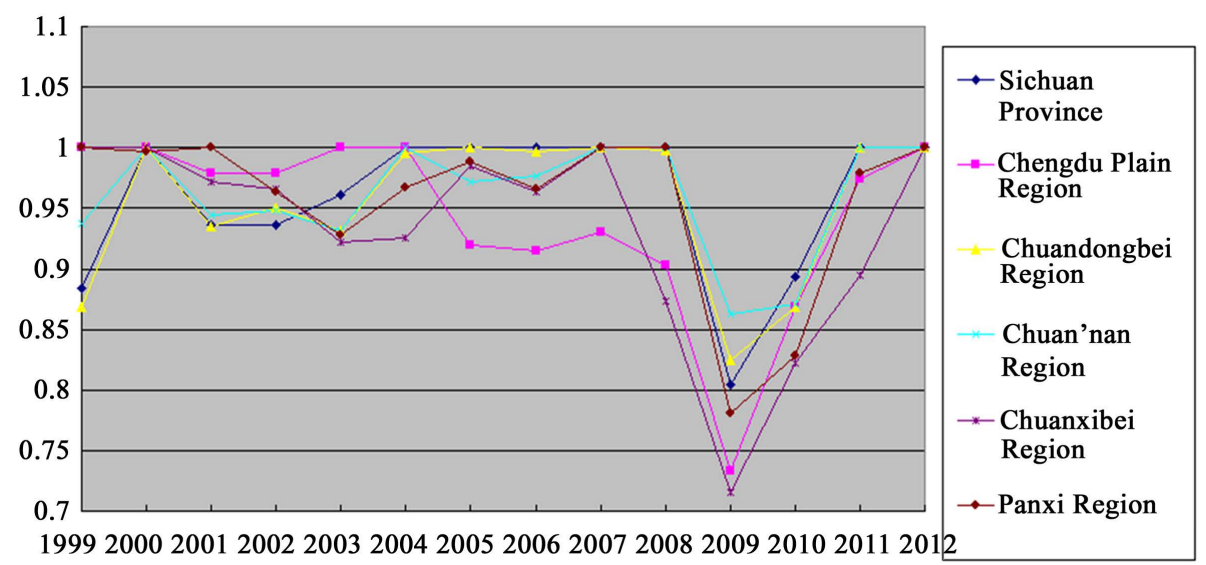

Figure 1. Change patterns of the overall input-output efficiency ratios in different land-use regions of Sichuan province.

a more and more outstanding role in regional development [7]. It is therefore highly necessary to study the contribution rate of every individual factor of production, including construction land, in different regions, and to rely on such measures as more balanced assignment of construction land quota to promote regional socio-economic development.

The allocation of construction land should be based on a comprehensive analysis of overall efficiency. In addition, it should also help to maintain a balanced economic development for different regions while ensuring the implementation of the provincial government's multiple growth points and economic zone-based development strategy. In order to achieve this, it is essential to adhere to the principle of emphasizing efficiency without at the expense of equity in the allocation of construction land so that both efficiency and a balanced regional economic growth will be achieved. At present, Sichuan Provincial People’s Government is making vigorous efforts to implement its multiple growth points and economic zone-based development strategy. So the allocation of construction land should also be carried out in compliance with this strategy. On the one hand, the leading position of Chengdu as the capital of the province should be enhanced to ensure its role as the model of growth. On the other hand, the economic zones of Chuan'nan, Chuandongbei, and Panxi should enjoy more priority regarding the assignment of construction land quota so that the creation of more growth zones will be backed by constant supplies of resources.

The only effective way to tackle the contradiction between land demand and supply is to apply stringently the basic principle of economical and intensive utilization of land to construction land to improve its utilization efficiency. This will be achieved by full compliance with the requirements of limiting supply increases strictly, making full use of existing supply, optimizing structure, and improving efficiency. At the same time, effective supervision of the utilization of construction land will be further enhanced by scientifically made land-use standards and sound land-use system. In this process, the ways in which land is utilized and economic development is pursued will be ameliorated to lay a solid foundation for the construction of a moderately prosperous society.

\section{References}

[1] Zhang, L.Q., Chen, S.P. and Chen, B.P. (2013) The Contribution of Land to the Economic Growth and Inflection Point of Its Logistic Curve in Anhui Province in Recent 15 Years. Scientia Geographica Sinica, 34, 40-46.

[2] Hao, W.B. and Wang, K.Y. (2014) A Study of the Contribution Rate of Land in Urban Economic Growth: Based on Panel Data Analysis of Hebei Province between 2003 and 2012. Hebei Enterprises, 8, 38-39.

[3] Zhao, X.B. (2013) A Theoretical Study of the Relationship of Economic Growth and Land Factors within the Framework of New-Classical Theory. Commercial Times, 11, 25-26.

[4] Li, B. and Hao, W.B. (2013) A Quantitative Analysis of the Effects of Urban Land on the Secondary and Tertiary Industries: A Case Study of Ten Major Cities around Bohai Bay. Economic Research Guide, 15, 172-175.

[5] Yang, S., Hu, W.H. and Li, S.P. (2013) Study on the Non-Effective Improvement of Productive Efficiency of Cultivated Land in Shaanxi Province Based on DEA. China Land Sciences, 10, 62-68. 
[6] Ye, J.P., Ma, C.F. and Zhang, Q.H. (2011) Contribution of Land to the Economic Growth of China: Based on Spatial Panel Data Model. Finance \& Trade Economics, 4, 111-116.

[7] Chen, W., Yan, C.Q. and Wu, Q. (2011) Study on the Contribution of Land Element to Economic Growth of Development Zones: Based on Panel Data Estimation and Measurement in Jiangsu Province. Areal Research and Development, 30, 146-149. 